\title{
CYP2D6*42 Allele
}

National Cancer Institute

\section{Source}

National Cancer Institute. CYP2D6*42 Allele. NCI Thesaurus. Code C46059.

Human CYP2D6*42 allele is located in the vicinity of 22q13.1 and is approximately $4 \mathrm{~kb}$ in length. This allele, a variant form of the CYP2D6 wild-type allele, encodes cytochrome P450 2D6*42 protein. The CYP2D6*42 allele exhibits a two nucleotide insertion (g.3259insGT) that results in a frameshift during protein coding. This alteration abolishes the enzymatic activity of the cytochrome P450 2D6*42 protein. 